\title{
Recombinant Vaccinia-gp100:209-217
}

National Cancer Institute

\section{Source}

National Cancer Institute. Recombinant Vaccinia-gp100:209-217. NCI Thesaurus. Code C29566.

A recombinant vaccinia virus encoding a modified peptide of the gp100 melanomamelanocyte antigen with potential use in cancer immunotherapy. gp100 human antigen is a wild type self-antigen expressed by melanocytes, pigmented retinal cells and most melanomas. gp100p209 is a fragment epitope of gp100 in which the threonine in position 2 is replaced with methionine; this modification may stimulate tumor infiltrating lymphocytes (TIL) more efficiently. (NCI04) 